\title{
Glutathione Biosynthesis in Human Erythrocytes
}

\author{
I. IDENTIFICATION OF THE ENZYMES OF \\ GLUTATHIONE SYNTHESIS IN HEMOLYSATES
}

\author{
Virginia Minnich, M. B. Smith, M. J. Brauner, and \\ Philip W. Majerus \\ From the Departments of Internal Medicine and Biochemistry, Washington \\ University School of Medicine, St. Louis, Missouri 63110
}

\begin{abstract}
A в S T R A C T The two enzymes required for de novo glutathione synthesis, glutamyl cysteine synthetase and glutathione synthetase, have been demonstrated in hemolysates of human erythrocytes. Glutamyl cysteine synthetase requires glutamic acid, cysteine, adenosine triphosphate (ATP), and magnesium ions to form $\boldsymbol{\gamma}$ glutamyl cysteine. The activity of this enzyme in hemolysates from 25 normal subjects was $0.43 \pm 0.04 \mu$ mole glutamyl cysteine formed per $\mathrm{g}$ hemoglobin per min. Glutathione synthetase requires $\boldsymbol{\gamma}$-glutamyl cysteine, glycine, ATP, and magnesium ions to form glutathione. The activity of this enzyme in hemolysates from 25 normal subjects was $0.19 \pm 0.03 \mu$ mole glutathione formed per $\mathrm{g}$ hemoglobin per min. Glutathione synthetase also catalyzes an exchange reaction between glycine and glutathione, but this reaction is not significant under the conditions used for assay of hemolysates. The capacity for erythrocytes to synthesize glutathione exceeds the rate of glutathione turnover by 150 -fold, indicating that there is considerable reserve capacity for glutathione synthesis. A patient with erythrocyte glutathione synthetase deficiency has been described. The inability of patients' extracts to synthesize glutathione is corrected by the addition of pure glutathione synthetase, indicating that there is no inhibitor in the patients' erythrocytes.
\end{abstract}

\section{INTRODUCTION}

It was initially demonstrated in 1955 (1) that the tripeptide glutathione (GSH) turns over with a $T_{1}$ of 4

This work was presented in part at the meeting of the American Society of Clinical Investigation, Atlantic City, N. J., May, 1970 (J. Clin. Invest. 49: 60a).

Dr. Majerus is a Teaching and Research Scholar of the American College of Physicians.

Received for publication 1 October 1970 and in revised form 2 November 1970. days in erythrocytes, suggesting that GSH must be continuously resynthesized. Since that time a number of experiments have suggested that rat $(2-4)$ and human $(1,5)$ erythrocytes can synthesize the glutathione. However, these attempts to demonstrate de novo synthesis of GSH by measuring glycine incorporation into GSH using erythrocytes or hemolysates were hampered by technical difficulties. Snoke and Bloch (6-8) demonstrated in yeast and in pigeon liver that GSH is synthesized by two enzymes which catalyze the following reactions :

1. Glutamic acid + cysteine + ATP

$$
\begin{aligned}
& \stackrel{\text { glutamyl cysteine synthetase }}{\longrightarrow} \\
& \mathrm{Mg}^{++} \\
& \gamma \text {-glutamyl cysteine }+\mathrm{ADP}+\mathrm{P}_{\mathbf{i}}
\end{aligned}
$$

2. $\gamma$-Glutamyl cysteine + glycine + ATP

$$
\underset{\mathrm{Mg}^{++}}{\stackrel{\text { glutathione synthetase } \mathrm{GSH}}{\longrightarrow}}
$$

These authors also demonstrated that GSH synthetase catalyzes an exchange reaction between glycine and preformed GSH (8). Thus, the demonstration of glycine incorporation into GSH using either intact erythrocytes or hemolysates could reflect either de novo synthesis or the exchange reaction. More recently, Sass (9) and Jackson (10) have demonstrated that de novo glutathione synthesis occurs in human erythrocytes.

We are now reporting the characterization of the two enzymes of GSH synthesis in erythrocytes. We have developed reproducible and relatively simple assays for these enzymes. Using these assays we have defined the normal levels of these enzymes in erythrocytes and have recently reported a family deficient in the enzyme GSH 
synthetase $(11,12)$. In a subsequent paper we shall report the purification and properties of these two enzymes from human erythrocytes.

\section{METHODS}

Preparation of erythrocyte extracts. Erythrocytes were isolated from 5-ml samples of blood collected in EDTA by centrifugation in a clinical centrifuge in conical, graduated glass tubes. The volume of packed erythrocytes was estimated after the cells were washed two times in isotonic saline. 10 volumes of cold distilled water were then added to the erythrocyte pellet and, after mixing, samples were taken directly for enzyme assay. In some experiments initial centrifugation to remove stroma was performed. These experiments demonstrated that all of the GSH synthetic activity was contained in the supernatant fraction. In most experiments this centrifugation step was omitted since the presence of stroma in reaction mixtures did not influence the results.

In other experiments leukocytes (13) and platelets (14) were isolated, and, after the pellets were diluted in distilled water, they were assayed for GSH and $\gamma$-glutamyl cysteine (GC) synthetase activity. These experiments indicated that less than $1 \%$ of the enzyme activity measured in the erythrocyte preparations could be due to the contaminating leukocytes and platelets.

Enzyme assays. Assay of both $\gamma$-glutamyl cysteine (GC) synthetase and GSH synthetase depends on the precipitation of the reaction products from incubation mixtures as cadmium mercaptides. Since these mercaptides are insoluble at neutral $\mathrm{pH}$ but are soluble in acid, the precipitates can be washed free of radioactive substrates with water and then dissolved in acid and counted. In preliminary experiments it was found that the use of Falcon disposable plastic tubes $(75 \times 12 \mathrm{~mm})$ greatly facilitated the handling and recovery of these precipitates (Falcon Plastics, Division of B-D Laboratories, Inc., Los Angeles, Calif.). When glass tubes were used, results were less reproducible due to difficulty in resuspending the precipitates during washing.

Glutathione synthetase. Reaction mixtures contained 15 $\mu$ moles Tris- $\mathrm{HCl}, \mathrm{pH}$ 8.25, $0.6 \mu$ mole ATP, $2.0 \mu$ moles dithiothreitol, $3 \mu$ moles magnesium chloride, $1.5 \mu$ moles glycine $-{ }^{14} \mathrm{C}(0.2 \mu \mathrm{Ci} / \mu$ mole $), 0.1 \mu$ mole $L-\gamma$-glutamyl cysteine, and enzyme in a volume of $0.173 \mathrm{ml}$. Reaction mixtures minus enzyme were initially preincubated at $37^{\circ} \mathrm{C}$ for $15 \mathrm{~min}$ to insure complete reduction of $\gamma$-glutamyl cysteine. The $\mathrm{pH}$ of the final reaction mixture was 8.0 due to the acidic $\gamma$-glutamyl cysteine and glycine. Reactions were started by the addition of enzyme. After incubation at $37^{\circ} \mathrm{C}$ for $30 \mathrm{~min}$, reactions were stopped by the addition of 0.2 $\mathrm{ml}$ of $9 \%$ trichloroacetic acid (TCA) containing $0.1 \mathrm{M}$ imidazole. (Imidazole is added to facilitate reaching the end point in the subsequent titration step.) When crude hemolysates were assayed, it was helpful to remove the precipitated protein at this stage by centrifugation of the reaction mixtures at $2000 \mathrm{~g}$ for $10 \mathrm{~min}$. The resulting supernatant solutions were then added to Falcon plastic tubes, each of which contained $4 \mu$ moles of carrier GSH, $12.5 \mu$ moles cadmium chloride, and $0.03 \mathrm{ml}$ of indicator in a total volume of $0.1 \mathrm{ml}$. (The indicator solution was prepared by mixing

\footnotetext{
${ }^{1}$ Majerus, P. W., M. J. Brauner, M. B. Smith, and V. Minnich. Glutathione synthesis in human erythrocytes. II. Purification and properties of the enzymes of glutathione biosynthesis. In preparation.
}

equal parts of $0.04 \%$ aqueous solutions of bromcresol green and bromcresol purple.) Reaction mixtures were then titrated by the dropwise addition of $0.5 \mathrm{~N}$ sodium hydroxide to a characteristic aqua color. If a blue color was reached, the reaction mixture was back-titrated with 7\% TCA. At this point GSH was quantitatively precipitated. (Largescale incubations were carried out to characterize this end point. The $\mathrm{pH}$ of the reaction mixture at the end point was $5.25 \pm 0.05$, and the ratio of optical density at $410 \mathrm{~m} \mu$ / $610 \mathrm{~m} \mu$ was 0.75 . Slight variation in the final ratio did not affect the results, and with experience these titrations could be carried out rapidly.) Water was then added to a final volume of about $2 \mathrm{ml}$ to wash any remaining acid or base from the sides of the tubes, and additional adjustment of the $\mathrm{pH}$ was made where necessary. After centrifugation at $2000 \mathrm{~g}$ for $8 \mathrm{~min}$, the precipitates were suspended and washed in $2 \mathrm{ml}$ of water. This procedure was accomplished by mixing twice on a Vortex mixer (Scientific Industries, Inc., Springfield, Mass.). The precipitates were washed three times in this manner. The final precipitates were dissolved in $0.5 \mathrm{ml}$ of $7 \%$ trichloroacetic acid and then counted in a liquid scintillation counter in $10 \mathrm{ml}$ of Bray's solution (15). No quench corrections are necessary when using this system, since TCA quenches minimally in Bray's solution. When hemolysates were assayed, $0.5-3.0 \mathrm{mg}$ of hemoglobin were contained in each reaction mixture. Blank values were determined by the addition of glycine $-{ }^{14} \mathrm{C}$ after the addition of TCA to reaction mixtures. Hemoglobin concentration was measured by the method of Drabkin (16).

Glutamyl cysteine synthetase. Assays for GC synthetase were performed using the same general procedure as for GSH synthetase. Reaction mixtures contained $40 \mu$ moles of imidazole- $\mathrm{HCl}, \mathrm{pH} 8.25,4.0 \mu$ moles of cysteine- $\mathrm{HCl}, 1.2$ $\mu$ moles ATP, $4 \mu$ moles dithiotreitol, $6 \mu$ moles magnesium chloride, $3.6 \mu$ moles $\mathrm{L}$-glutamic acid- ${ }^{3} \mathrm{H}(0.17 \mu \mathrm{Ci} / \mu$ mole $)$ and enzyme in a volume of $0.346 \mathrm{ml}$. Reactions were started with the addition of glutamic acid and were incubated $1 \mathrm{hr}$ at $37^{\circ} \mathrm{C}$. The $\mathrm{pH}$ of the reaction mixtures was 7.5 since cysteine was added as its hydrochloride. Reactions were stopped by the addition of $0.03 \mathrm{ml}$ of $60 \%$ trichloroacetic acid. The remainder of the assay procedure was identical to that used to measure GSH synthetase. When hemolysates were assayed, $0.5-3.0 \mathrm{mg}$ of hemoglobin $(\mathrm{Hb})$ were contained in the reaction mixtures. Blank values were determined as described above for GSH synthetase.

Reaction products. The product of the GC synthetase reaction was shown to be L- $\gamma$-glutamyl cysteine. A large-scale incubation (10 times the standard assay) was carried out to accumulate the reaction product of the GC synthetase reaction. In this and in the GSH synthetase reaction described below dithiothreitol was omitted from the reaction mixture to prevent any possible formation of mixed disulfides with this compound in the subsequent oxidation step. After the reaction was stopped, the TCA was extracted from the incubation mixture with ether. The $\mathrm{pH}$ was then adjusted to 9.0 with $\mathrm{NaOH}$ and air was bubbled through the solution until all of the sulfhydryl groups of the reaction mixture were oxidized. The $\mathrm{pH}$ of the reaction mixture was then adjusted to 2.2 and the reaction mixture was poured onto a $1.5 \times 25 \mathrm{~cm}$ column of Bio-Rad AG $50 \times 8 \quad(200-400$ mesh) Bio-Rad Laboratories, Richmond, Calif. cation exchange resin previously equilibrated with 0.032 M pyridine acetate, $\mathrm{pH}$ 2.92. In previous experiments it was shown that glutamic acid, glycine, cysteine, GSH, and GC were eluted from this column using $0.032 \mathrm{M}$ pyridine acetate, $\mathrm{pH} 2.92$, while oxidized GSH, GC, and cysteine were retained on the column and could subsequently be eluted with $0.1 \mathrm{M}$ pyridine 
acetate, $\mathrm{pH}$ 3.1. Thus, glutamic acid- ${ }^{3} \mathrm{H}$ was separated from the radioactive product of GC synthetase. Fractions containing the radioactive product eluted with $0.1 \mathrm{M}$ pyridine acetate were pooled, lyophilized, and redissolved in $\mathrm{H}_{2} \mathrm{O}$. Aliquots of this product were then analyzed on the standard long column for protein hydrolysates of a Beckman 120C automatic amino acid analyzer (Fig. 1). The column eluate was assayed for radioactivity and ninhydrin reactivity. Oxidized, chemically synthesized $\boldsymbol{\gamma}$-glutamyl cysteine was eluted as a distinct peak between serine and glutamic acid.

The product of the GSH synthetase reaction was shown to be GSH in a similar manner. A large-scale GSH synthetase incubation and subsequent air oxidation of the reaction product was followed by chromatography on the AG 50 column described above. The radioactive reaction product was completely separated from the substrate glycine $-{ }^{14} \mathrm{C}$. This reaction product was then chromatographed on the amino acid analyzer (Fig. 1). Authentic glutathione disulfide (GSSG) is eluted between aspartic acid and threonine. Aliquots of the reaction product were also oxidized with performic acid (17) and then hydrolyzed for $22 \mathrm{hr}$ in constant boiling $\mathrm{HCl}$ in sealed evacuated tubes (18).

Materials. Glycine- ${ }^{14} \mathrm{C}$ and L-glutamic acid-- ${ }^{3} \mathrm{H}$ were purchased from New England Nuclear Corp., Boston, Mass.; t-Boc-L-glutamic acid- $\gamma$-benzyl ester and L-cystine dimethyl ester $2 \mathrm{HCl}$ were purchased from Fox Chemical Co., Los Angeles, Calif.

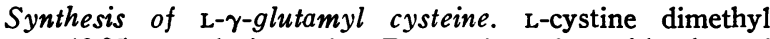
ester (2.95 mmoles) and $\mathrm{t}$-Boc-L-glutamic acid- $\gamma$-benzyl ester ( 5.9 mmoles) were dissolved in $20 \mathrm{ml}$ of dichloromethane. $N$-ethynylmethyldiethylamine (19) (5.9 mmoles dissolved in $5 \mathrm{ml}$ dichloromethane) was added slowly and the mixture was stirred for $2 \mathrm{hr}$ at room temperature. The reaction mixture was then filtered and the filtrate was washed with 0.5 M citric acid, $\mathrm{H}_{2} \mathrm{O}$, and saturated sodium bicarbonate. The reaction mixture was dried over sodium sulfate, filtered, and evaporated to dryness; the product was then recrystallized from ethyl acetate using petroleum ether. The product was then dissolved in $40 \mathrm{ml}$ trifluoroacetic acid and $\mathrm{HBr}$ was bubbled through the mixture for $30 \mathrm{~min}$ to remove the $\mathrm{t}-\mathrm{Boc}$ and benzyl ester groups. The product was precipitated by the addition of ether and then saponified in $1 \mathrm{M}$ sodium hydroxide: dioxane:: $1: 6$ for $2 \mathrm{hr}$ at room temperature. The solution was neutralized with $\mathrm{HCl}$ and the product was precipitated by the addition of ethanol. The final product was examined by amino acid analysis and nuclear magnetic resonance spectroscopy and the results of these studies were consistent with the structure of $L-\gamma$-glutamyl cystine. Alternatively, L- $\gamma$-glutamyl cystine was purchased from Cyclo Chemical Corp., Los Angeles, Calif. Either of these preparations served equally well as substrate for GSH synthetase. $\gamma$-Glutamyl cystine was reduced to $\gamma$-glutamyl cysteine by dissolving $0.1-0.5 \mathrm{~g}$ of $\gamma$-glutamyl cystine in $2.0 \mathrm{ml}$ of $0.2 \mathrm{M}$ Tris $\mathrm{HCl}, \mathrm{pH} 9.0$. The solution was then cooled to $4^{\circ} \mathrm{C}$ and $5.0 \mathrm{ml}$ of $1.5 \mathrm{M}$ potassium borohydride was added. After incubation for 15 min at $37^{\circ} \mathrm{C}$, the solution was cooled and acidified to $\mathrm{pH} 4$ with $4 \mathrm{M} \mathrm{HCl}$. After centrifugation to remove the precipitated potassium borate, the $\boldsymbol{\gamma}$-glutamyl cysteine content of the solution was assayed using 5,5'-dithiobis-2-nitrobenzoic acid (DTNB) (20).

\section{RESULTS}

The enzymes of glutathione synthesis can be measured in crude hemolysates and the properties of these enzymes are given below. We have also purified these enzymes extensively and studies of the purified enzymes are given in the subsequent report. ${ }^{1}$

Glutamyl cysteine synthetase. GC synthetase was assayed as described in Methods. The reaction was linear with time for at least $1 \mathrm{hr}$ and was also linear with respect to the amount of hemolysate added, up to 3.0 $\mathrm{mg}$ hemoglobin. The requirements for this reaction are

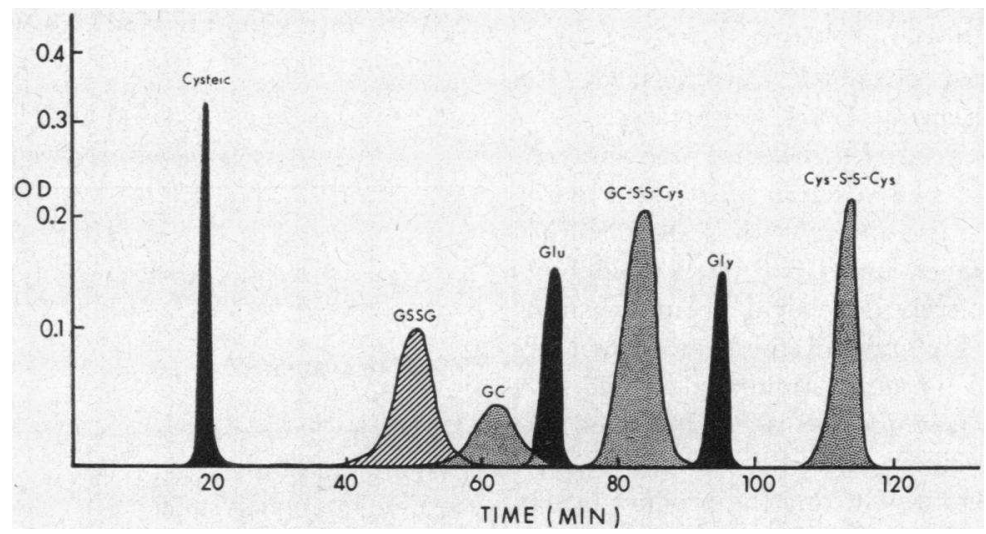

Figure 1 Chromatography of reaction products on a Beckman 120C automatic amino acid analyzer. The stippled curves represent the chromatogram of the isolated, oxidized product of GC synthetase. Both the peaks corresponding to oxidized GC and the mixed disulfide of GC and cysteine were radioactive. The striated curve represents the chromatogram of the isolated oxidized product of GSH synthetase which corresponds to authentic GSSG. The chromatogram of the performic acidoxidized, acid-hydrolyzed product of GSH synthetase is shown in the solid curve. In this experiment $1.3 \mu$ moles cysteic acid, $1.2 \mu$ moles glutamic acid, and $1.1 \mu$ moles glycine were eluted. 
TABLE I

Glutamyl Cysteine Synthetase

\begin{tabular}{cc}
\hline Additions or omissions & GC formed \\
\hline Complete system & mpmoles \\
- Cysteine & 66.3 \\
- ATP & 12.1 \\
- $\mathrm{MgCl}_{2}$ & 2.6 \\
- Dithiothreitol & 0 \\
\end{tabular}

Reaction mixtures containing $2.5 \mathrm{mg}$ hemoglobin were incubated as described in Methods with the omissions as noted above.

shown in Table I. The reaction is completely dependent on ATP and magnesium ions and largely dependent on cysteine. When purified GC synthetase was studied, there was complete dependence on added cysteine. The reaction is stimulated 3-fold by dithiothreitol. It is not clear whether this stimulation results from maintaining the enzyme in a reduced state, or whether dithiothreitol maintains the reaction product in its reduced form, thus allowing its precipitation as the cadmium mercaptide. Studies of purified GC synthetase with sulfhydryl inhibitors suggest that sulfhydryl groups are important for enzyme activity. ${ }^{1}$ The product of this reaction was isolated as described in Methods and was demonstrated to be $\gamma$-glutamyl cysteine by chromatography on the amino acid analyzer as shown in Fig. 1. Three compounds were eluted which correspond to $\gamma$-glutamyl cysteine, cystine, and the mixed disulfide of $\gamma$-glutamyl cysteine and cysteine. Both $\gamma$-glutamyl cysteine and the mixed disulfide were radioactive. Further, the isolated reaction product replaced chemically synthesized GC as a substrate for homogeneous GSH synthetase.

Glutathione synthetase. GSH synthetase was assayed as described in Methods. The reaction was linear with time for $30 \mathrm{~min}$ and was also linear with respect to the amount of hemolysate added, up to $3.0 \mathrm{mg}$ hemoglobin. GSH synthetase is completely dependent on magnesium ions and ATP, and on glutamyl cysteine as shown in Table II. This reaction is also stimulated 3 -fold by dithiothreitol. Since GSH synthetase is not inhibited by sulfhydryl poisons, it is likely that dithiothreitol functions to maintain the substrate GC and the product GSH in a reduced state. ${ }^{1}$ The oxidized substrate, $\gamma$-glutamyl cystine, was not metabolized by GSH synthetase as shown in Table II.

Snoke and Bloch demonstrated that GSH synthetase from yeast catalyzes an exchange of glycine into preformed GSH (8). Although this reaction proceeded at only $1 / 10$ the rate of glycine incorporation into GSH in the presence of glutamyl cysteine, other investigators have pointed out that glycine incorporation into GSH in erythrocytes could reflect this exchange reaction rather than de novo net GSH synthesis. We added GSH to assays for GSH synthetase to evaluate the magnitude of this exchange reaction. In the standard hemolysate assay there is approximately $0.05 \mu$ mole of GSH which is derived from erythrocyte GSH. This level of added GSH produced essentially no glycine incorporation, while $1 \mu$ mole of added GSH (which approximates the intracellular GSH concentration) results in some exchange of glycine into preformed GSH (Table II).

The oxidized product of GSH synthetase was isolated as described in Methods and was then analyzed by chromatography on the amino acid analyzer as shown in Fig. 1. This compound was eluted in the position of authentic GSSG. Further evidence that the product was GSSG was obtained by demonstrating that the reaction product served as a substrate for glutathione reductase. Amino acid analysis of the performic acid-oxidized and acid-hydrolyzed reaction product disclosed equimolar amounts of glycine, glutamic acid, and cysteic acid (also shown in Fig. 1).

Glutathione synthesis in erythrocytes from normal subjects. The enzymes of GSH synthesis were measured in hemolysates from 25 normal subjects. GC synthetase levels were $0.43 \pm 0.04$ (SD) $\mu$ mole GC formed per $\mathrm{g} \mathrm{Hb}$ per min, while GSH synthetase activity was $0.19 \pm 0.03$ (SD) $\mu$ mole GSH formed per $\mathrm{g} \mathrm{Hb}$ per min. Enzyme levels were identical in males and females. This study indicates that GSH synthetase is rate limiting for over-all GSH synthesis in erythrocytes. The activity of GSH synthetase in erythrocytes also suggests that the erythrocyte may have considerable reserve capacity to regenerate GSH by de novo synthesis. Thus,

TABLE II

Glutathione Synthetase

\begin{tabular}{|c|c|}
\hline Additions or omissions & $\begin{array}{c}\text { GSH } \\
\text { formed }\end{array}$ \\
\hline & mumoles \\
\hline Complete system & 8.3 \\
\hline$-\mathrm{ATP}$ & 0 \\
\hline$-\mathrm{MgCl}_{2}$ & 0 \\
\hline - Dithiothreitol & 2.5 \\
\hline$-\mathrm{L}-\gamma$-glutamyl cysteine & 0.1 \\
\hline$-\mathrm{L}$ - $\gamma$-glutamyl cysteine $+0.05 \mu$ mole GSH & 0.15 \\
\hline -L- $\gamma$-glutamyl cysteine $+1.0 \mu$ mole GSH & 1.1 \\
\hline -L- $\gamma$-glutamyl cysteine, & \\
\hline $\begin{array}{l}\text { - dithiothreitol } \\
+0.2 \mu \text { mole } \mathrm{L}-\gamma \text {-glutamyl cystine }\end{array}$ & 0 \\
\hline
\end{tabular}

Reaction mixtures contained $2.0 \mathrm{mg}$ hemoglobin and were incubated as described in Methods with the additions or omissions noted above. Reaction mixtures contained approximately $0.05 \mu$ mole GSH derived from the hemolysate. 


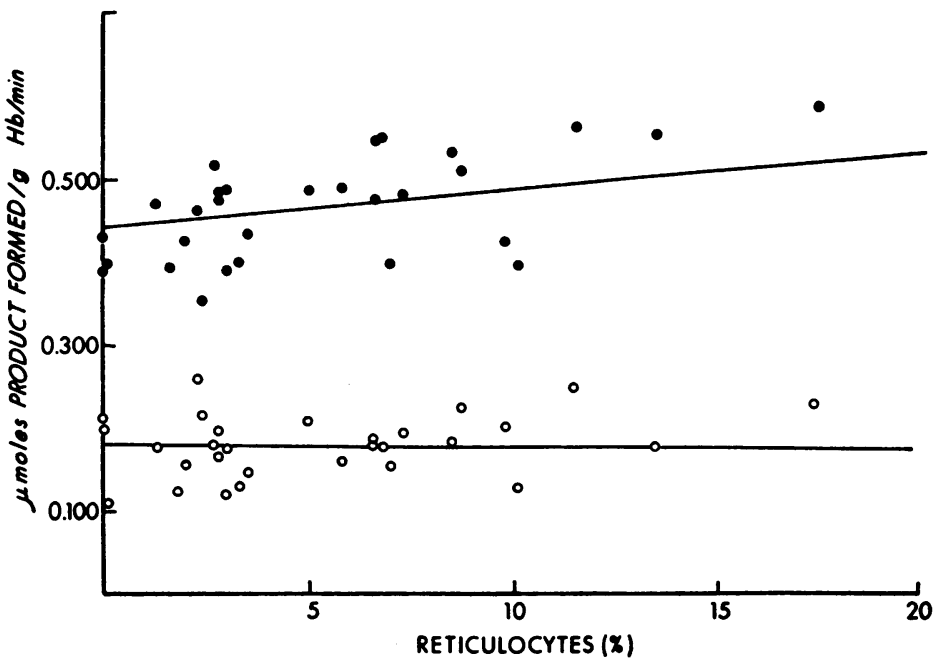

Figure 2 Effect of cell age on the enzymes of GSH synthesis. Blood samples from patients with acquired hemolytic anemia and from normal subjects were fractionated into "reticulocyte-rich" and "reticulocyte-poor" fractions by differential centrifugation. Hemolysates of these fractions and of the unfractionated erythrocytes were assayed for GC synthetase $(\bullet)$ and GSH synthetase $(O)$ activity. The lines are plotted by the method of least mean squares.

Dimant et al. (1) have shown that erythrocyte GSH turns over with a $t_{\frac{1}{2}}$ of 4 days, while GSH synthetase could potentially regenerate $\frac{1}{2}$ of the erythrocyte $\mathrm{GSH}$ in 40 min. $^{2}$

In order to evaluate the effect of cell age on the enzymes of GSH synthesis, samples of blood from patients with acquired hemolytic anemias and normal subjects were fractionated into reticulocyte-rich and reticulocytepoor fractions by differential centrifugation. Enzyme levels were compared to reticulocyte count as shown in Fig. 2. There is no effect of reticulocyte count on GSH synthetase levels, while GC synthetase levels are slightly higher in reticulocyte-rich blood. The correlation of GC synthetase with reticulocyte count is of borderline statistical significance, however $(t=2.0$, when $t=2.05$ $P<0.05)$. When enzyme levels were measured in a patient with pyruvate kinase deficiency (not shown in Fig. 1) with $80 \%$ reticulocytes, GC synthetase activity was $0.46 \mu$ mole $\mathrm{GC}$ formed per $\mathrm{g} \mathrm{Hb}$ per min, while GSH synthetase activity was $0.17 \mu$ mole $\mathrm{GSH}$ formed per $\mathrm{g} \mathrm{Hb}$ per min, further suggesting that the levels of these enzymes are not strongly dependent on cell age. It is of interest that GC synthetase is more unstable in vitro ${ }^{1}$ than $\mathrm{GSH}$ synthetase, which is in agreement with this in vivo data.

Glutathione synthetase deficiency. We have reported a patient with GSH synthetase deficiency $(12,13)$ who has a compensated hemolytic disorder with erythrocyte

\footnotetext{
${ }^{2}$ Assuming an erythrocyte GSH level of $15 \mu \mathrm{moles} / \mathrm{g}$ hemoglobin.
}

GSH levels $10-20 \%$ of normal. The levels of GC synthetase in the patient and his family were normal. We have now measured GSH synthetase in the relatives of this patient. The GSH synthetase levels, shown in Fig. 3, indicate an autosomal inheritance for this enzyme deficiency. The heterozygous family members have normal erythrocyte GSH levels, normal hemoglobins, and normal reticulocyte counts. The propositus hemoly-

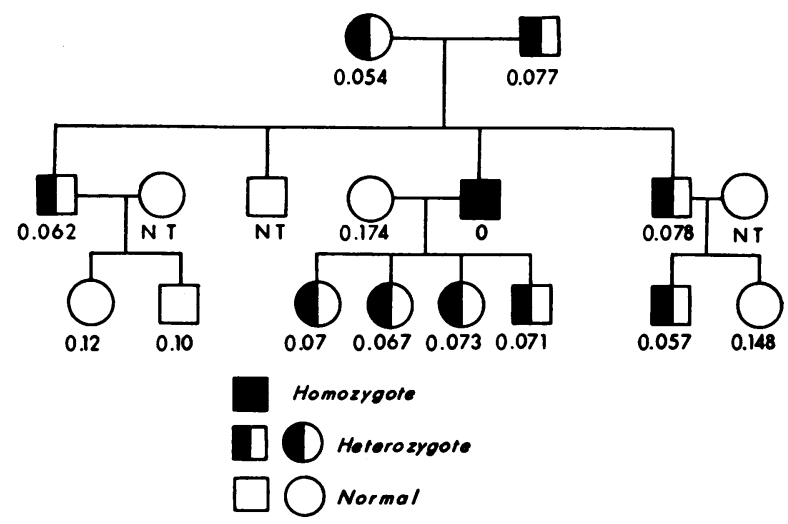

FIgURE 3 Pedigree of family with GSH synthetase deficiency showing GSH synthetase activity expressed as $\mu$ mole of $\mathrm{GSH}$ formed per gram $\mathrm{Hb}$ per minute. The normal value for controls collected with these samples was 0.14 \pm 0.05 (SD) $\mu$ mole GSH formed per $\mathrm{g} \mathrm{Hb}$ per min. This somewhat low value for control patients results from the fact that assays were performed 6-10 hr after blood was collected. This time was required for shipment of samples in ice to St. Louis. NT, not tested. 
TABLE III

Glutathione Synthesis in Hemolysates from Propositus

\begin{tabular}{|c|c|c|c|c|}
\hline \multirow[b]{2}{*}{ Enzyme } & \multicolumn{3}{|c|}{ Substrates added } & \multirow[b]{2}{*}{$\begin{array}{l}\text { GSH-14C } \\
\text { formed }\end{array}$} \\
\hline & GC & $\begin{array}{l}\text { Glu- } \\
\text { tamic } \\
\text { acid }\end{array}$ & $\begin{array}{l}\text { Cys- } \\
\text { teine }\end{array}$ & \\
\hline \multirow{6}{*}{$\begin{array}{l}\text { Propositus hemolysate } \\
\text { Propositus hemolysate } \\
\text { Propositus hemolysate } \\
\text { + GSH synthetase } \\
\text { Propositus hemolysate } \\
\text { + GSH synthetase }\end{array}$} & & & & (mpmoles) \\
\hline & + & - & - & 0 \\
\hline & - & + & + & $\mathbf{0}$ \\
\hline & + & - & - & 40 \\
\hline & & & & \\
\hline & - & + & + & 34 \\
\hline
\end{tabular}

Reaction mixtures contained $\mathrm{ATP}, \mathrm{MgCl}_{2}$, glycine-14 $\mathrm{C}$, and the addition noted above as described in Methods. GSH synthetase $(0.006) \mathrm{mg}$ used in this experiment was homogeneous enzyme free of $\mathrm{GC}_{\text {s }}$ synthetase activity. The propositus hemolysate added to each reaction contained $2.5 \mathrm{mg}$ hemoglobin.

sate was unable to catalyze the synthesis of GSH from either the constituent amino acids or from GC and glycine as shown in Table III. Homogeneous GSH synthetase was added to the patient's hemolysate to exclude the possibility that this defect was due to an inhibitor of GSH synthetase. GSH synthetase corrected the inability of the hemolysate to catalyze the synthesis of GSH from GC. Added glutamic acid and cysteine replaced the requirement for $\mathrm{GC}$, indicating that $\mathrm{GC}$ synthetase was present in the hemolysate.

Since the patient's erythrocytes contained some GSH as measured with DTNB, we next examined the possibility that the sulfhydryl compound in the patient's erythrocytes was GC rather than GSH. In these experiments the mercaptan was isolated from the patient's cells as described in Methods. After air oxidation this compound was tested as a substrate for glutathione reductase. These experiments indicated that the sulfhydryl compound in the patient's erythrocytes is not GC, since it serves as a substrate for glutathione reductase. Oxidized GC is inactive as a substrate for glutathione reductase. This experiment does not exclude the presence of low levels of GC in the patient's erythrocytes. Since the patient's erythrocytes contain low levels of GSH, his immature erythrocytes must have the capacity to synthesize GSH. Either the mutant enzyme is unstable and is thus absent in circulating erythrocytes, or it is destroyed in the preparation of hemolysates for assay. This latter alternative is somewhat unlikely, since the patient's erythrocytes failed to incorporate significant amounts of glycine ${ }^{14} \mathrm{C}$ into $\mathrm{GSH}$ when fresh, intact cells were incubated with glycine- ${ }^{14} \mathrm{C}(21)$.

\section{DISCUSSION}

Much of the previous uncertainty about the ability of erythrocytes to synthesize GSH de novo has derived from the fact that experiments were carried out using intact cells or hemolysates which contained large amounts of GSH. Failure to measure the enzymes of GSH synthesis directly led to uncertain interpretation of radioactive incorporation data. Recently Sass (9) showed an increment in total GSH in hemolysates after incubation with glycine, glutamic acid, cysteine, and ATP, indicating some de novo synthesis of GSH. We have demonstrated and quantitated the levels of GSH synthesizing enzymes in hemolysates. Furthermore, we have described assays for each of the enzymes and have demonstrated that exchange of glycine into preformed GSH is not a problem using this technique. When glycine incorporation into GSH is measured using intact cells, some exchange probably occurs (Table II), although the bulk of the incorporation reflects de novo synthesis. Jackson (10) has reported GSH synthetase levels 5-fold higher than those reported here. The assay used by this author is indirect and does not distinguish between the substrate GC and the product GSH. Since the substrate concentration used was 200 -fold greater than the GSH product formed, it may be difficult to measure accurately product formation in the presence of large amounts of GC using this technique.

Several patients with presumed GSH synthetase deficiency have been described previously, although heterozygotes were not detected in these studies since direct enzyme assays were not used $(22,23)$. The level of GSH in heterozygotes is normal, so that they can be detected only by measuring GSH synthetase directly. The frequency of GSH synthetase deficiency is unknown, although it must be rare. Whether heterozygotes are susceptible to drug-induced hemolysis remains to be determined. In the future it should be possible to screen patients with Heinz body anemias for deficiency of the enzymes of GSH synthesis, since the assays are not difficult and the substrates are commercially available.

The physiological role of GSH synthesis in red cell metabolism remains to be elucidated. The relatively great capacity for GSH synthesis suggests that this pathway may be important in protecting cells against oxidative stress. This may be especially true in patients with deficiency of one of the other enzymes of the oxidative pathway. Thus, Srivastava and Beutler (24) demonstrated that erythrocytes are permeable to oxidized glutathione. When the capacity to reduce GSSG is impaired, cells may lose their glutathione. In this situation de novo GSH synthesis may be important in restoring cellular levels of GSH. Jacob and Jandl (25) demonstrated that, after $90 \%$ of intracellular GSH was alkylated in vitro with $N$-ethylmaleimide, erythrocytes survived normally when transfused back to the donors. This may be explained by the fact that GSH synthesis could restore normal levels of GSH in these cells within $1 \mathrm{hr}$, assuming that one can extrapolate in vitro enzyme activity to the in vivo situation. Under normal circumstances this 
pathway functions at a low level relative to its capacity and the cellular GSH level remains constant. The mechanism by which the pathway is regulated to maintain $\mathrm{GSH}$ levels is unknown.

\section{ACKNOWLEDGMENTS}

We wish to thank Dr. Garland Marshall for his help in synthesizing $\gamma$-glutamyl cystine and in performing NMR spectra on the synthesized compound. We also wish to acknowledge our collaboration with Dr. Daniel Mohler in the study of the family with GSH synthetase deficiency.

This investigation was supported in part by Grants AM 10550 and HE 00022 from the U. S. Public Health Service, and Grant PRA 33 from the American Cancer Society.

\section{REFERENCES}

1. Dimant, E., E. Landsberg, and I. M. London. 1955. The metabolic behavior of reduced glutathione in human and avian erythrocytes. J. Biol. Chem. 213: 769.

2. Elder, H. A., and R. A. Mortensen. 1956. The incorporation of labeled glycine into erythrocyte glutathione. J. Biol. Chem. 218: 261.

3. Mortensen, R. A., M. I. Haley, and H. A. Elder. 1956. The turnover of erythrocyte glutathione in the rat. J. Biol. Chem. 218: 269.

4. Kasbekar, D. K., and A. Sreenivasan. 1959. Biosynthesis of glutathione by rat erythrocytes. Biochem. J. 72: 389 .

5. Hochberg, A., M. Rigbi, and E. Dimant. 1964. The incorporation in vitro of glycine and L-glutamic acid into glutathione of human erythrocytes. Biochim. Biophys. Acta. 90: 464.

6. Snoke, J. E., S. Yanari, and K. Bloch. 1953. Synthesis of glutathione from $\gamma$-glutamylcysteine. J. Biol. Chem. 201: 573 .

7. Mandeles, S., and K. Bloch. 1955. Enzymatic synthesis of $\gamma$-glutamylcysteine. J. Biol. Chem. 214: 639.

8. Snoke, J. E., and K. Bloch. 1955. Studies on the mechanism of action of glutathione synthetase. J. Biol. Chem. 213: 825.

9. Sass, M. D. 1968. Glutathione synthesis in cell-free preparations from erythrocytes of different ages. Clin. Chim. Acta. 22: 207.

10. Jackson, R. C. 1969. Studies in the enzymology of glutathione metabolism in human erythrocytes. Biochem. J. $111: 309$.
11. Majerus, P. W., V. Minnich, and D. Mohler. 1970. De novo biosynthesis of glutathione in extracts from human erythrocytes. J. Clin. Invest. 49: 60 a. (Abstr.)

12. Mohler, D. N., P. W. Majerus, V. Minnich, C. E. Hess, and M. D. Garrick. 1970. Glutathione synthetase deficiency as a cause of hereditary hemolytic disease. $N$. Engl. J. Med. 283: 1253.

13. Majerus, P. W., and R. Lastra. 1967. Fatty acid biosynthesis in human leukocytes. J. Clin. Invest. 46: 1596.

14. Majerus, P. W., M. B. Smith, and G. H. Clamon. 1969. Lipid metabolism in human platelets. I. Evidence for a complete fatty acid synthesizing system. J. Clin. Invest. 48 : 156.

15. Bray, G. A. 1960. A simple efficient liquid scintillator for counting aqueous solutions in a liquid scintillation counter. Anal. Biochem. 1: 279.

16. Drabkin, D. L. 1945. Crystallographic and optical properties of human hemoglobin. A proposal for the standardization of hemoglobin. Amer. J. Med. Sci. 209: 268.

17. Hirs, C. H. W. 1956. The oxidation of ribonuclease with performic acid. J. Biol. Chem. 219: 611.

18. Spackman, D. H., W. H. Stein, and S. Moore. 1958. Automatic recording apparatus for use in the chromatography of amino acids. Anal. Chem. 30: 1190.

19. Buyle, R., and H. G. Viehe. 1964. Peptidsynthesen mit Inaminen. Angew. Chem. 76: 572.

20. Ellman, G. L. 1959. Tissue sulfhydryl groups. Arch. Biochem. Biophys. 82: 70.

21. Mohler, D. N., C. E. Hess, M. D. Garrick, and N. Eby. 1970. Glutathione synthetase (GS) deficiency hereditary hemolytic anemia. Clin. Res. 18: 80.

22. Prins, H. K., M. Oort, J. A. Loos, C. Zürcher, and T. Beckers. 1966. Congenital nonspherocytic hemolytic anemia associated with glutathione deficiency of the erythrocytes. Hematologic, biochemical and genetic studies. Blood. 27 : 145.

23. Boivin, P., and C. Galand. 1965. La synthèse du glutathione au cours de l'anémie hémolytique congénitale avec déficit en glutathion réduit. Déficit congénital en glutathion-synthétase érythrocytaire? Nouv. Rev. Fr. Hématol. 5 : 707.

24. Srivastava, S. K., and E. Beutler. 1969. The transport of oxidized glutathione from human erythrocytes. J. Biol. Chem. 244: 9.

25. Jacob, H. S., and J. H. Jandl. 1962. Effects of sulfhydryl inhibition on red blood cells. II. Studies in vivo. J. Clin. Invest. 41: 1514. 